\title{
Porencephaly and intraparenchymal hyperacute infarct due to bilateral anterior cerebral artery embolism in adult: A rare case
}



\author{
Ricky Suryamin ${ }^{1}$, Subagia Santosa Sudjono \\ ${ }^{1}$ General Practitioner, Department of Radiology, University of Christian Krida Wacana, ${ }^{2}$ Radiologist, Department of \\ Radiology, Mayapada Hospital, Tangerang, Indonesia
}

\section{A B S T R A C T}

Porencephaly is a very unique rare neurological disease identified by the presence of single or multiple cerebrospinal fluid (CSF) cyst inside the brain matter. This is an intra-cranial cyst that rarely occurs in adults. The diagnosis depends on a well-defined CSF fluid spaceoccupying lesion (SOL) that communicates with the ventricles on a CT scan or MRI of the brain. Cerebral damage during labor or as unknown trauma during infancy can present with porencephaly much later in life. This might be the aftermath of trauma, ischemic, infection or bleeding in the postnatal life. These cysts may be mild enough to show any symptoms or severe enough to cause mental and physical disability. Here we present a case of a 76-year-old female attended in the emergency department with loss of strength in her right arm, four days ago. Porencephaly in adult is a rare neurological disease case. In this case, porencephaly caused by stroke ischemic 4 years ago due to anterior carotid artery embolism.

Key words: Porencephaly; cerebrospinal fluid; MRI; space-occupying lesion
Access this article online

Website:

http://nepjol.info/index.php/AJMS

DOI: 10.3126/ajms.v12i6.34593

E-ISSN: 2091-0576

P-ISSN: $2467-9100$

Copyright (c) 2021 Asian Journal of Medical Sciences

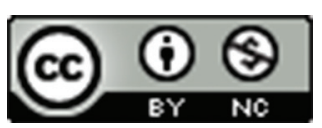

This work is licensed under a Creative Commons Attribution-NonCommercial 4.0 International License.

\section{INTRODUCTION}

Porencephaly is a very unique rare neurological disease indentify by the presence of single or multiple cerebrospinal fluid (CSF) cyst inside the brain matter. This is an intracranial cyst that rarely occurs in infants/children especially adults. ${ }^{1}$ It is inherited or acquired cyst within the cerebral/cerebellar hemisphere. It contains CSF with thin walls covered by a spongiotic or gliotic white matter which commonly communicates directly with the brain ventricle. The size varies considerably. It can be unilateral or bilateral, cortical or subcortical, and is frequently seen in the region provided by cerebral arteries. It has been encouraged that porencephalic cysts are originated by disorder of the blood vessel supply leading to degeneration of the brain. ${ }^{2}$ Acquired cysts are caused by injury such as infection, ischemia, trauma or surgery. ${ }^{3}$ The clinical representation may varies with the size and location of the cyst. The patient may be asymmptomatic or present with seizure, neurological deficit, motor deficit or mental retardation.

\section{CASE PRESENTATION}

This is a case of a 76-year-old female presented to emergency department with loss of strength in her right arm four days ago. The patient could not walk with history of ischemic stroke 4 years ago. No history of any food or drug allergies observed in the past. She has uncontrolled high blood pressure for the past nine years, but were not on antihypertensive drugs in a routinely. On presentation, her pulse was $104 /$ minute, respiratory rate $23 /$ minute 
with saturation $95 \%$ in room air, blood pressure $160 / 95$, no ronchi in both lungs with positive pupillary light reflex direct and indirect. Her siriraj score was -1 with no menigeal sign. She was able to speak, but was less active with no evidence of seizure. She was given intravenous citicoline (500mg), intravenous piracetam ( $3 \mathrm{~g}$ ), oral cilostazol (50mg). The magnetic resonance imaging with diffusion weighted image sequence showed an hyperacute infarct in left side of the brain (Figure 1), while there was right thin wall cyst that was connected to the third ventricle (Figure 2) in T2-weighted image and magnetic resonance angiography showed absence of both anterior carotid artery (Figure 3).

Four years ago, she was diagnosed with ischemic stroke and treated in hospital for 3 weeks, after discharged she went for follow up to the neurologist for the stroke and her hypertension, later she discontinued the consultation with the neurologist due to financial constraints and her children were living outside the city. On daily basis, after recovery she was helping her husband selling food at foodstall infront of their house. A month earlier, her husband observed that she was having loss of appetite and lost strength in her right arm four days ago, when she called her children and was brought to the emergency department for clinical check-up.

\section{DISCUSSION}

Inherited heterozygous mutation in COL4A1, encodes Type IV A1 collagen chains that are important for the formative integrity of the vascular basal membrane, has been described in people with porencephaly. ${ }^{2}$ The diagnosis of COL4A1-related disorders is made in patients with suggestive features and identification of heterozygous pathogenic variants in COL4A1. Once the pathogenic variant COL4A1 has been identified in affected family members, prenatal testing and genetic diagnosis prior to implantation for pregnancies at high risk for COL4A1related disorders can be performed. ${ }^{3}$ Hypoperfusion causes localized necrosis of gray and white matter, localized encephalomalacia, and eventually cystic degeneration. The

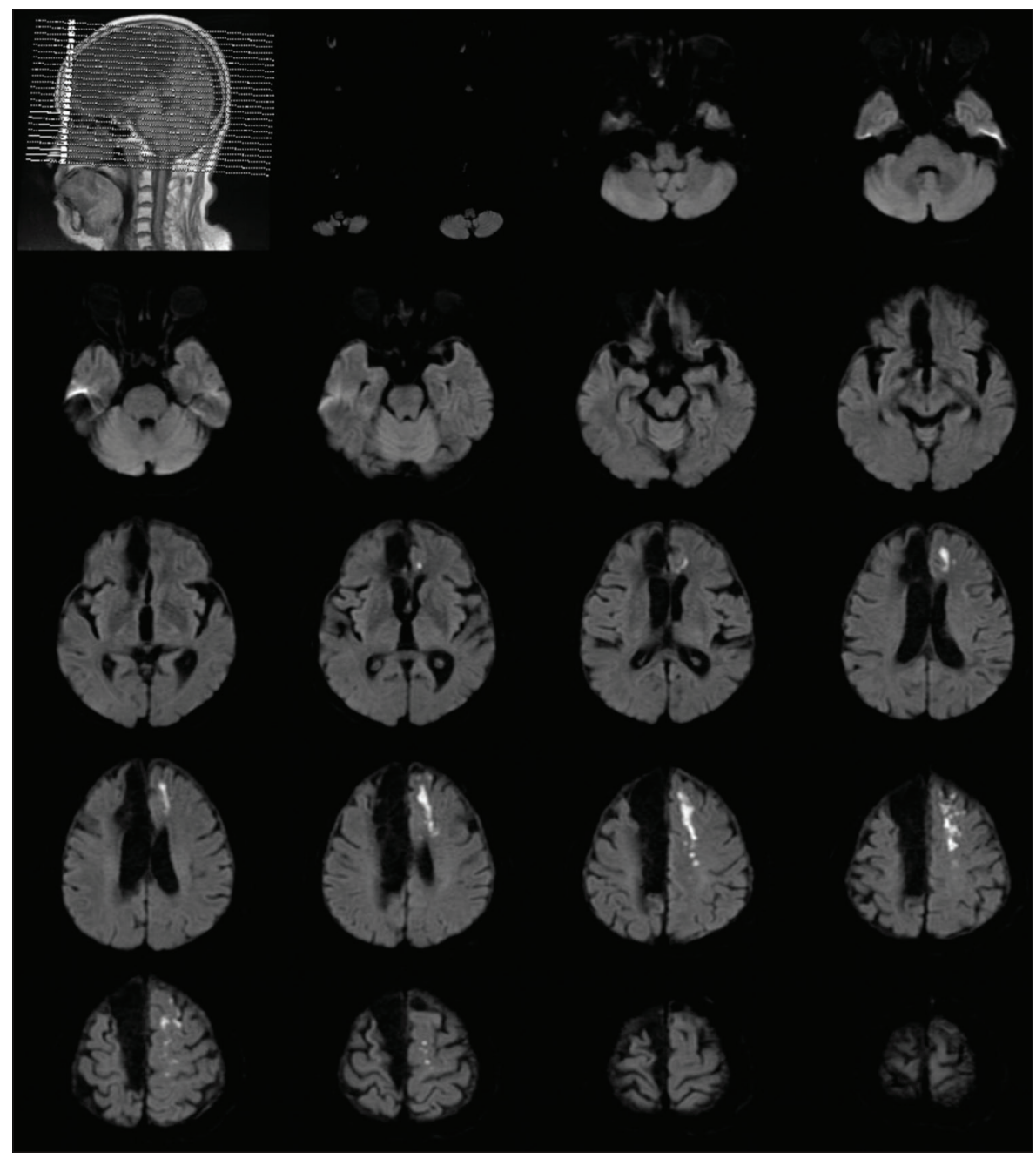

Figure 1: Brain magnetic resonance imaging (MRI) Diffusion Weighted Image (DWI). Hypointense lesion in the right frontal lobe. Hyperintense lesion in left gyrus rectus (frontal lobe) 


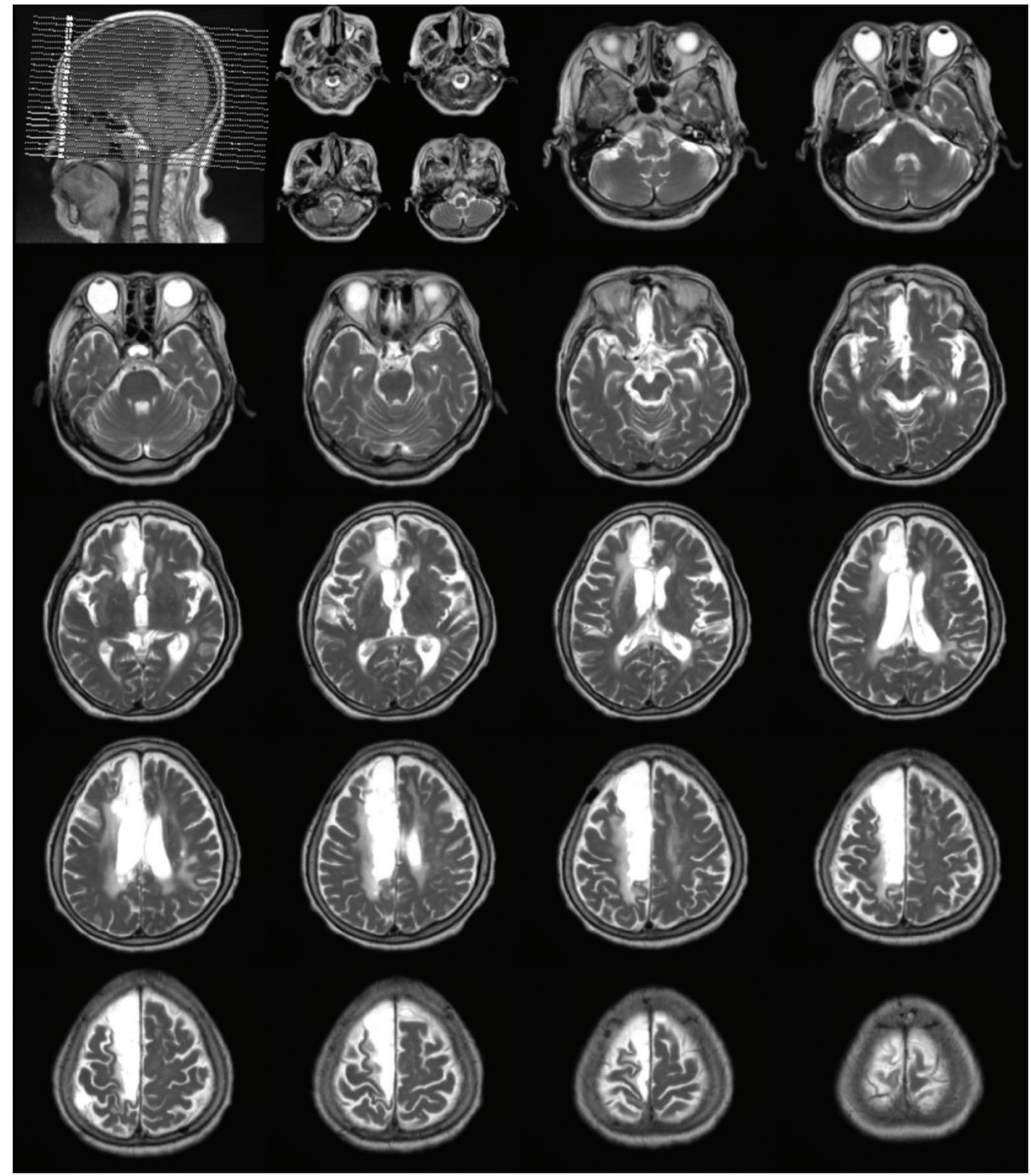

Figure 2: Brain MRI T2-Weighted image. A moderate well-defined cyst in the right gyrus rectus has communication with right ventricle. Periventricular deep white matter change (Fazekas II). It follows CSF signal in all sequences. With no diffusion or restriction and mass effect

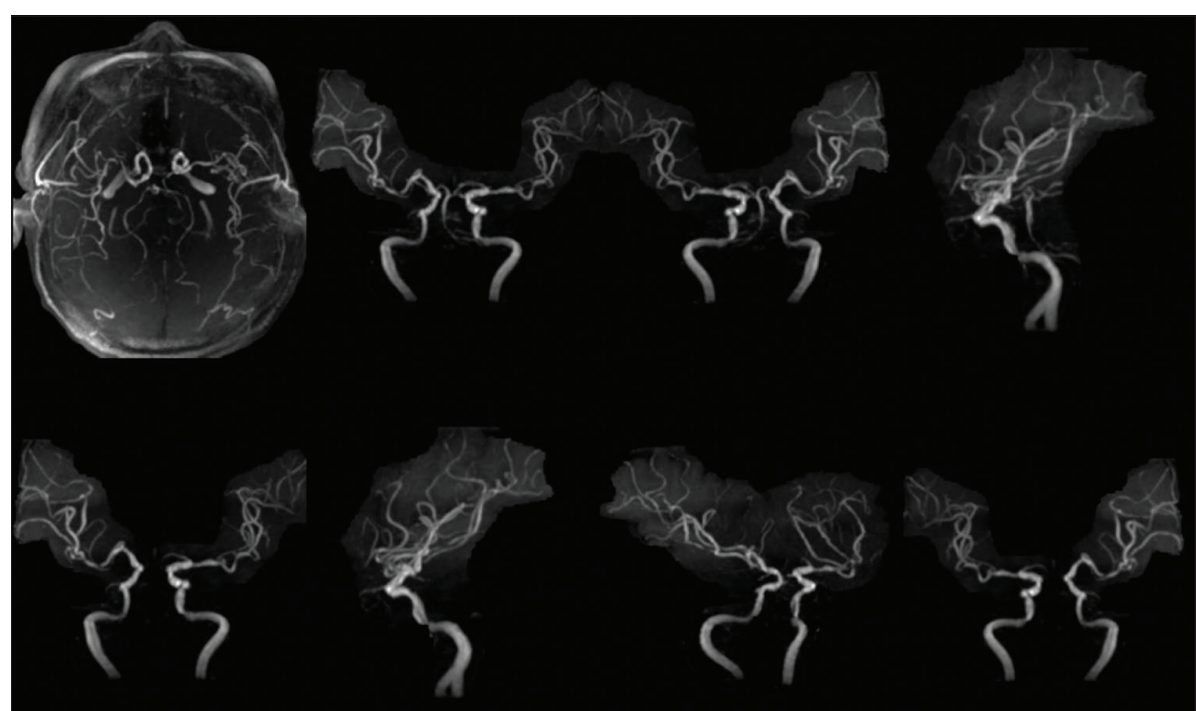

Figure 3: Brain magnetic resonance angiography. Both left and right anterior carotid artery (A1) are not visible

pathological process of the symptoms is not well known, but many elements can provoke manifestations in patients, including traumatic life events and injuries. Symptoms can emerge impulsively, without any known stimulant. ${ }^{1}$ There 
have been reports of porencephaly with $\mathrm{CO}$ poisoning, cognitive dysfunction, psychosis, CMV infection, dermoid cysts, and myesthenia gravis. ${ }^{4}$

The clinical features with the size and location of the cysts may vary. Patients can be symptomless or might present with focal neurological deficits, seizure disorder, or mental defect. Seizures can be focal or tonic-clonic. Limb deficits scale from hemiparesis to severe symmetrical paralysis. Mental deficits alter starting with normal or slight learning disabilities to severe mental defect. Microcephaly is generally related. ${ }^{5,6}$

The differential diagnosis of porencephaly includes schizencephaly, arachnoid cyst, cystic neoplasm and hydrocephalus. In schizencephaly there are fissures with smooth outline while in porencephaly, the cysts are round with jagged contours and there may be thrombus or detritus. Intra-uterine MRI can be considerate in third trimester to see if the obstruction is coated with white or gray matter. Arachnoid cysts commonly has smooth outline, not symmetrical and do not communicate with the lateral ventricles. They also have mass effects not seen in porencephaly. Cystic carcinoma are rare and also has a combination of solid and cystic portion with mass effect. Hydrocephalus can easily be differentiated from porencephaly by their characteristics of hydrocephalus. ${ }^{4}$

Porencephaly treatments and its possible difficulty include physiotherapy for neurological defects, control seizures with anti-epileptic drugs, and shunts if hydrocephalus develops. Surgical options are suggested for cases that are unaffected by anti-epileptic drugs. Hemispherotomy and hemispherectomy options should be included. Identifying the source of intraparenchymal bleeding and arterial thrombosis is essential.

\section{CONCLUSION}

Porencephaly in adult is a rare neurological disease case. It is a congenital or acquired disease. Acquired cysts are caused by injury such as infection, ischemia, trauma or surgery.
In this case, porencephaly was caused by stroke ischemic 4 years ago due to anterior carotid artery embolism. Treatment include physiotherapy for neurological defects, control seizures with anti-epileptic drugs, and shunts if hydrocephalus develops. Surgical option can be thought if antiepileptic drugs are resistant.

\section{ACKNOWLEDGEMENTS}

We thank the family of the woman described for allowing us to share her details.

\section{REFERENCES}

1. Al-Thafar Al, Al-Rasheed AS, Al-Matar BA, Al-Sharydah AM, AlAbdulwahhab AH and AI-Suhibani SS. An Atypical Porencephalic Cyst Manifesting as a Simple Partial Seizure: A Case Report and Literature Review. Case Reports in Neurological Medicina. 2017; Volume 7.p.1-4.

https://doi.org/10.1155/2017/2174045

2. Oomen AT, Sethy G, Minz NT, Patra J and Panda SS. Unusual Presentation of Porencephalic Cyst in an Adult. Journal of Clinical and Diagnostic Research. 2017; Vol-11(2):OD12-OD13. https://doi.org/10.7860/JCDR/2017/22654.9374

3. Osborn AG. Porencephalic cyst. Diagnostic imaging. Brain. Salt Lake City, Utah: Amirsys. 2004;1:7-36.

4. Bhuta P, Bhalodiya D and Muley A. Porencephaly: case report and review. Journal of Intergrated Health Sciences. 2016; Vol IV: 52-55.

https://doi.org/10.4103/2347-6486.240046

5. Kokkinos V, Garganis K, Kontogiannis K and Zountsas B. Hemispherotomy or lobectomy? The role of presurgical neuroimaging in a young case of a large porencephalic cyst with intractable epilepsy. Pediatric Neurosurgery. 2011;47(3):204-209. https://doi.org/10.1159/000330546

6. Ozeki M, Funato M, Teramoto T, Ohe N, Asano T, Kaneko H, et al. Reversible cerebrospinal fluid oedema and porencephalic cyst, a rare complication of ventricular catheter. Journal of Clinical Neuroscience. 2010;17(5):658-661. https://doi.org/10.1016/j.jocn.2009.07.122

7. Hasbani GE, Balaghi A, Assaker R, Rojas A, Troyal M, Kpfahi A, et al. Intraparenchymal hemorrhage and cerebral venous thrombosis in an adult with congenital porencephalic cyst presenting for generalized tonic-clonic seizures. Elsevier: 2020; Radiology Case Reports. 2020;15:.99.

https://doi.org/10.1016/j.radcr.2019.10.028

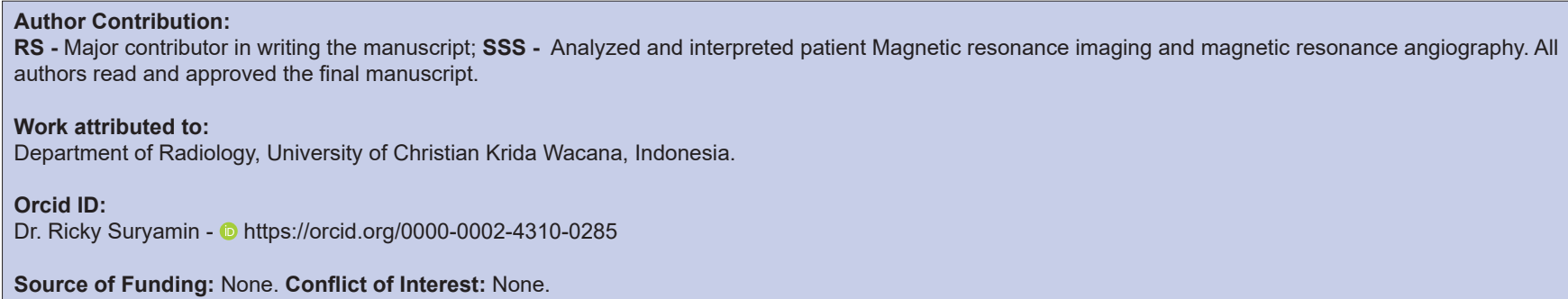

